\title{
Govt steps up to stop corrosion of health research
}

Government is to fund $1000 \mathrm{PhDs}$ across health disciplines over the next decade and add clinical research centres to hospitals earmarked for revitalisation so that it can build relevant evidence-based knowledge into the public health system - and begin tackling the crisis in clinical research.

These are among its first responses to specific recommendations in a concise 8-page report produced last year after a national health research summit in Gauteng in July. The summit drew on two groundbreaking sets of findings: the September 2009 Lancet Journal series on the health of South Africans and the Academy of Science of South Africa's recommendations for revitalising clinical research. ${ }^{1}$

Deputy Minister of Health, Dr Gwen Ramokgopa, told an audience that included some of South Africa's top health scientists at a dinner in Cape Town on 26 April this year that her department was currently spending $0.6 \%$ of its budget on health research. This is woefully short of the $2 \%$ minimum it committed to in its own 2001 health research policy, let alone at the Global Ministerial Forum on Research for Health in Bamako, Mali, 4 years ago. However, she said she had 'no doubt' that this target could be achieved over the next ' 3 - 5 years'. (The reiterated local recommendation is for government to spend R2 billion on health research over the next 3 years to get to $2 \%$ of budget.) Ramokgopa challenged scientists to come up with projects and programmes that would 'lend themselves to being part of this $2 \%$ - align yourselves with government priorities and render

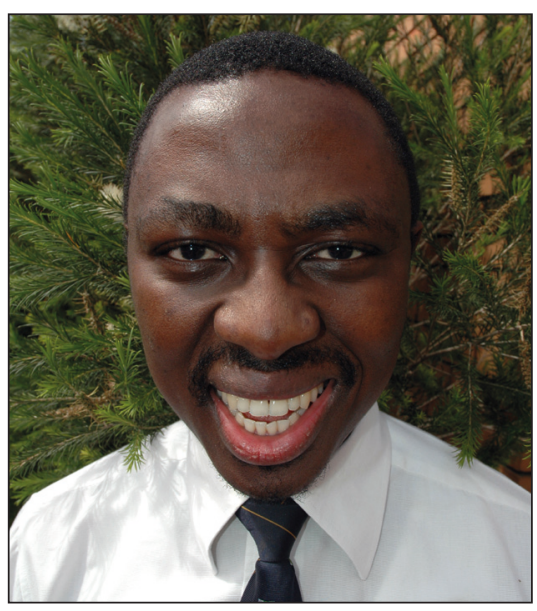

Prof. Bongani Mayosi, Head of the NHRC and Head of the Department of Medicine at UCT.

yourselves fundable, she advised. The new national health scholarships would begin this year, bankrolling $30 \mathrm{PhD}$ candidates through local and foreign universities and rising to 300 scholars within four years and 1000 over 10 years. Ramokgopa challenged the private health sector to match her department 'rand for rand' so the country could exceed its research scholar targets. (Several large health corporations already sponsor $\mathrm{PhD}$ programmes.) The first clinical research centres within academic health complexes will be at the Polokwane Mankweng Tertiary Hospital Complex and King Edward Hospital. Ramokgopa said 'invaluable interactions' between the Medical Research Council (under Professor Lizo Mazwai) and the National Health Research Committee (NHRC) had helped her department identify gaps and priorities. Besides education, her government had identified health as the top priority, alarmed by the doubling of the national mortality rate during the first 15 years of democracy. A belated but aggressive response to this had so far halved HIV transmission from mothers to children and reduced the turnaround time for TB diagnoses from 6 weeks to about 2 hours, plus improved TB outcomes through combination drug therapies. The National Health Insurance (NHI) system would over the next 14 months pilot 10 districts via accreditation of facilities, injecting the latest research and innovation and leveraging scarce human resources via the private sector by engaging with GPs and private practitioners.

'We want an integrated single health system that will respond optimally to the (quadruple) disease burden ... and actionable, clear recommendations that take us to the high road of research and innovation', she said.

\section{Committee chief lists research woes}

Prof. Bongani Mayosi, head of the NHRC, a statutory body advising the health department on priorities, resources, policy framework and the co-ordination of health research, said the average South African's health had gone backwards, with life expectancy down from 70 years in 1990 to just over 50 currently. Of the historical corrosion of the country's 'crucible of knowledge creation' (research), he said less than $1 \%$ of all healthcare professionals in the country currently had a $\mathrm{PhD}$ as an addition to their professional degree. 
Also 'we have five or less black African clinician scientists with a strong record of published papers - in other words real scholars - that's pretty bad. Why? Well, we've simply not invested in producing them. The future of our country rests on the way we address this, he stressed. ${ }^{2}$

He listed the problems affecting the state of clinical research as: inadequate funding, too few health researchers (many of them world class, but mostly ageing), a lack of facilities, creeping 'managerialism' with the National Health Laboratories charging more than the biggest private labs to do research, the lack of a clinical trials funding body and a woeful regulatory regimen for approving trials, new devices and products. There was also little, if no, planning and monitoring and evaluation. 'We need to build a system for health research. Rather than prioritising diarrhoea, for example, we need robust systems that respond to the patient with $\mathrm{TB}$ and diabetes all in one - that's where the key shift must occur, he said. The test of success would be how quickly the life expectancy of South Africans improved.

Ramokgopa told Izindaba that the latest figures from Statistics SA showed that a reversal in life expectancy had already occurred with an improvement of 2 - 3 years. 'We took too long to respond to the HIV epidemic; until civil society stood up. But today we are using the best available scientific knowledge and the lives of South Africans are improving. She said nearly all the recommendations listed by Prof. Mayosi were 'actionable in the short term'. However, translating research into programmes that everyone could understand and carry out and general planning for national needs, plus monitoring and evaluation, would take a few years longer.

Prof. Jerry Coovadia, Victor Daitz Professor at the Nelson Mandela School of Medicine at the University of KwaZuluNatal, founder member of the Academy of
Science of South Africa and a member of the National Planning Commission, lauded the comprehensive NHRC report.

'In this document we see some of the research priorities influenced by the government's commitments to its 10-point health plan and its negotiated service delivery plan. It looks at some of the key killers, deals with disease priorities and fits disease and morbidity with other Millennium Development Goals and other African goals, ${ }^{3}$ he said.

\section{Chris Bateman}

chrisb@hmpg.co.za

1. Mayosi BM, Dhai A, Folb P, et al. Revitalising Clinical Research in South Africa: A Study on Clinical Research and Related Training. Pretoria: Academy of Science of South Africa, 2009. http://www.assaf.co.za/wp-content/uploads/2009/09/ASSAfClinical-report-2009.pdf

2. Bateman C. SA's clinical research output in crisis. S Afr Med J 2011:101(9);614-616

3. Mayosi B, Mekwa N, Blackburn J, et al. (NHRC members), Strengthening research for health, innovation and development in South Africa. 2011 National Health Research Summit Report. 